\title{
Research on the paths of business model innovation
}

\author{
Shengzhou Wang \\ Hebei University of Economics and Business \\ Shijiazhuang, China \\ *Corresponding author: Shengzhou Wang,wsz00001@163.com
}

\begin{abstract}
Management must transform enterprise-centric into customer-centric with the big changing of the business environment. Business model is redefined. It is customer value demand-centric and constituted with value creation, value realization and value proposition. Business model interface is described as customer demand, product \& service, enterprise value activity and business revenue. To analyse customer demand, design product \& service, organize enterprise value activity, and create business revenue forms the paths of business model innovation base on the business model interface.
\end{abstract}

Keywords: business model; innovation; paths

Innovation is a familiar concept. All of you know that change has happened since the beginning of time. We are affected by it every day. Whether we choose to change or are forced to change out of necessity, it happens. ${ }^{1}$ Innovation is affecting not only organizations, but also our lives. Innovation is all around us. We can say that the only unchanged thing is change.

\section{Introduction}

Business model is not a new concept. Any enterprise has its own business model from the time it was founded. Now we need to think about what the business model is. What is the business model? It is a simple question, but it is not answered easily. In simple terms, business model is a complete set of ways to make money. It is a little bit different from sale model, operation model, management model etc. Business model is a system. It is a higher level than strategy. 


\section{Background}

Why do we have to carry out the business model innovation? Why do we need to change? We will think about background from three aspects: the business environment, technology and consumer.

\subsection{The change of the business environment}

We review the history of Socio-economic development. Business risk and uncertainty increased with the development from natural economy to agricultural economy, industrial economy and internet economy. Business environment has huge changed with the development from industrial economy to internet economy especially. We analyse the transition from the industrial economy to the Internet economy now, which we are experiencing. We have to be aware of it.

What is the difference between the industrial economy and the internet economy? What are the characteristics of the industrial economy or the internet economy? What does the industrial economy or the internet economy focus on? All of you know that the characteristics of the industrial society include specialization of labor, socialized production, etc. The industrial society focuses on quantity, productivity, efficiency, cost, product, price, process, technology, etc. Businesses improved efficiency by developing the assembly line. In this stage, especially in the early stage, the supply is less than the demand. Companies are enterprise-centric. But The characteristic of the internet economy includes more opening of information. At the same time, information can be transmitted more widely and quickly. People can connect more easily. Internet has changed the way people work and live entirely. Supply has exceeded demand in most areas. The organization in the internet situation focuses on customer, demand, service, overall solution etc. Companies must be customer-centric. Business model must be changed.

\subsection{The rapid development of technology and creative destruction}

Technology is a key factor to the development of company. Company must focus on the technology direction. It has to research and keep up with the developmental trend of technology. The technology development is a creative destruction. Amazon might replace the bookstore and digital camera replace the photographic film are because of the technology development and creative destruction. Internet technology, AI, VR, 3D and 4D etc. has absolutely changed today. Business model innovation is the top priority. 


\subsection{Consumer tastes and expectations have changed and will continue to change}

Rivalry is fiercer with the supply is greater than the demand. Rivalry begin to transfer from product, quantity, price, cost etc. to service, brand, value, innovation etc. Customer demandcentric model replace the enterprise-centric model. Business operations must be changed. The most important innovations must change the process from push to pull. What is the difference between push and pull? The main difference is that push is enterprise-centric and pull is customer-centric. The pushing begins from the upstream supply chain to the downstream supply chain. The pulling begins from the customer to the upstream supply chain. Each process has to locate the right product in the right time.

Any business must operate in certain situations and must adapt to the situations, otherwise its operation will encounter difficulties. The most pressing matter of the moment is business model innovation.

\section{Business model concept}

What is the business model? We should research the business model using system thinking, rather than fragmentary or partial understanding. I think the business model is customer value demand-centric. It is constituted by the relevant businesses and stakeholders. It is a value creation and value realization system that abides by the same value proposition. Business model should be an overall concept that is combined with the value proposition, the value creation and the value realization. The relationship of the value proposition, the value creation and the value realization is not a simple linear relationship, but a complete system. They are connected with each other and restricting each other, act and react upon one another, oppose each other but also complement each other. Customer value-centric is the root research of business model, because the business model begins with the customer value and finishes with the satisfaction of the customer value. The value proposition is that what value can be given to the customers, the enterprises, the relevant enterprises and the stakeholders. It is a whole value proposition. It includes not only bringing value to customers and businesses, but also to the relevant enterprises and stakeholders. We should define the value of each participant in this system. The value creation is what value can be created by each of the participants in this system. How to complement each other and increase the overall value? The value realization refers to how to get the value of each participant. In other words, how to get the profit, how to achieve a win-win goal and how to maintain and improve the operation of the system? Show in Fig.1. 


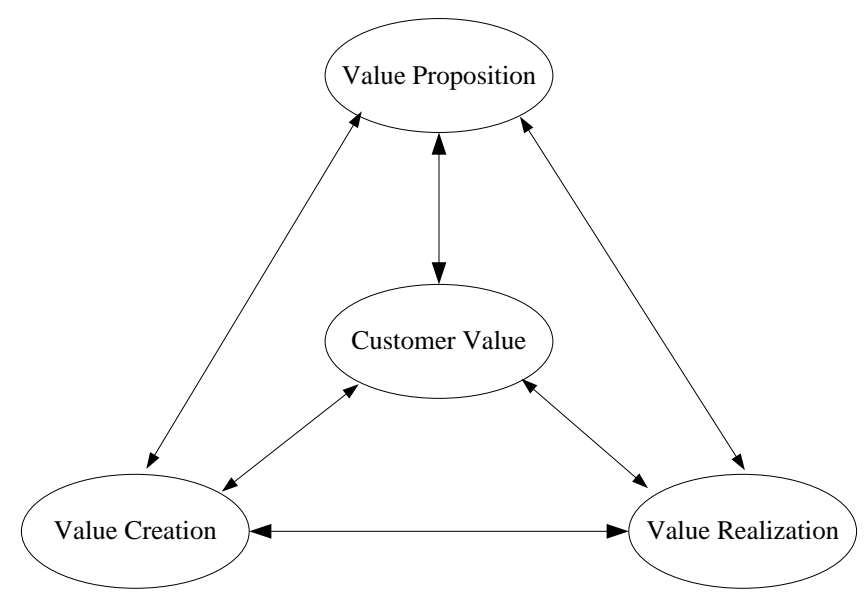

Fig. 1- Business model concept

In the past, it was enterprise-centric whatever the operation, the management, the structure, the process, the organization, the service etc. All of these are convenient for enterprise. Now it must be customer-centric. We have to change the business model and be convenient for the customer. In the past, organization adopted bureaucracy or hierarchy to increase efficiency. Now this structure must be changed. The organization must be more flexible. Team work or the learning organization is a good idea. It can be called "Orange Model". The core is customer demand and customer value. Each of the pieces of the orange is a team work or a learning organization. All operations should base around the customer value.

\section{Business model interface}

Business model concept is a system. Customer value, value proposition, value creation and value realization can be led into one platform. Four aspects combine a circle. Each factor is act and react upon one another. Customer value is the primary factor or the key factor. Business operation begins on customer value. Then the arrangement is value proposition, value creation and value realization. According to the business model concept, Business model interface can be built. Business model interface would be simplified in order to research the paths of business model innovation. Customer demand, product \& service, enterprise value activity and business revenue instead of customer value, value proposition, value creation and value realization. We get the specific business model interface. Show in Fig. 2. 


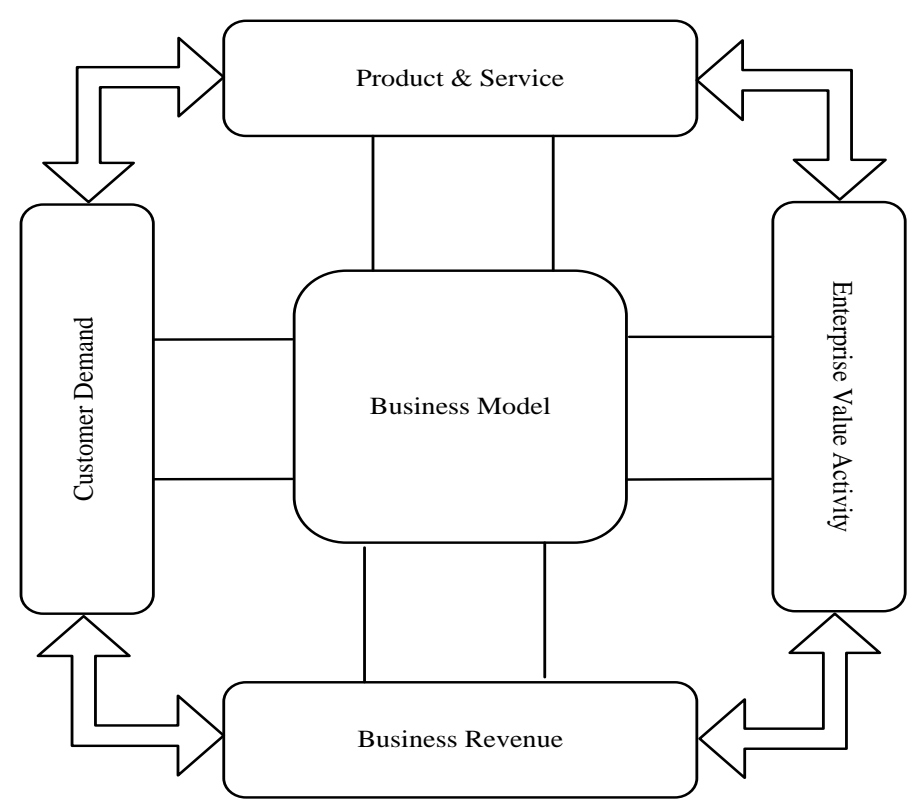

Fig. 2-Business model interface

Business model interface can be compared with Porter's five forces model. The Porter's five forces model is based on competition. It analyses the rivalry among existing firms, threat of new entrants, threat of substitute products, determinants of supplier power and determinants of buyer power. ${ }^{2}$ It just analyses the rivalry, the power, the threat between company and others. It is just a distribution concept. Existing value is distributed by stakeholders. It maximizes the value by itself. It is a win-lose situation. However, business model interface is based on collaboration. It is a creation concept. All of the stakeholders are partners. They work together to create value. They maximize the overall value. This is a win-win situation.

\section{Paths of business model innovation}

Base on the business model interface, paths of business model innovation can be got. Show in Fig.3.

\subsection{Find out the potential or truly demand of customer}

Customer demand is the core factor of business model innovation. It is the critical task which to study and find out the potential or truly demand. Investigation becomes an important method to obtain the potential or truly demand. At this stage, investigator need to talk with customer, discuss the dissatisfactory demand of the present product or service. Which way can you go into the customer? How can you get the potential or truly customer demand? How to evaluate the demand? How to choose the valuable discovery? Customer demand must be defined or described clearly at last. This is the premise of business model innovation. 


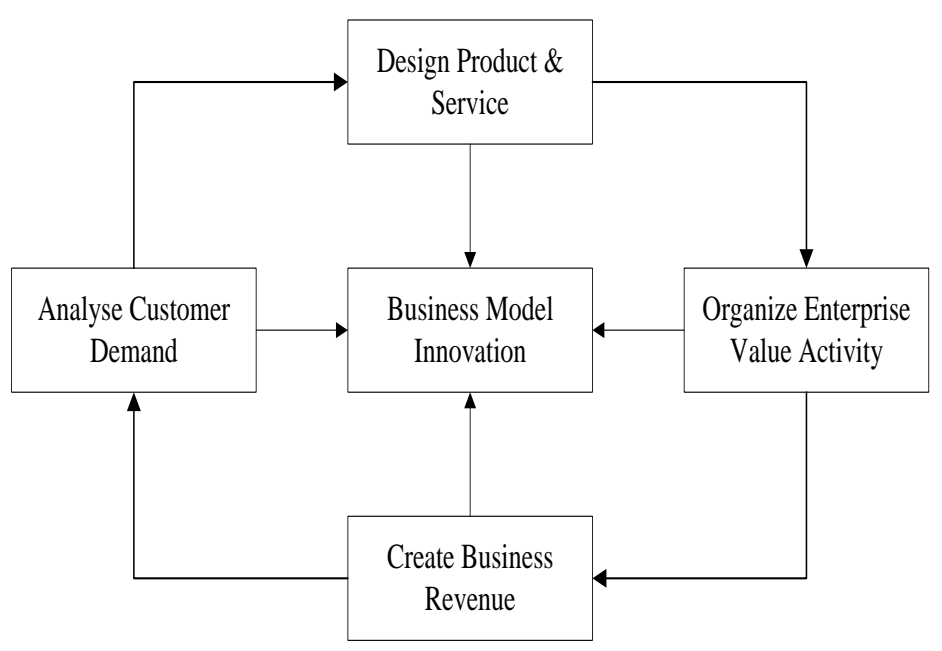

Fig. 3-Paths of business model innovation

\subsection{Design the product or service matching the demand}

According to the potential or truly demand of customer, product or service design is beginning. The product or service design is the root of enterprise operation. At the same time, this is a necessary condition for the competitive advantage. With the increase of competition, the customer has more and more competitive initiative. It is particularly important that design the product or service that meets the customer demand. ${ }^{3}$ This is the foundation of business model innovation.

\subsection{Organize the appropriate enterprise value activity}

The process, style or method must be changed. The business process reengineering becomes one of the important methods of this stage. The original business process must be studied newly. Which is the necessary process? Which is the unnecessary process? Which is the value-added activity? Which activity do not increase value? Which processes must be kept? Which are the activities that must be kept? Which processes can be deleted? Which activities are unnecessary? Operation process must be redefined by studying enterprise value activity. ${ }^{4}$ This is the core of business model innovation.

\subsection{Create Diverse Business Revenue}

The operation of the enterprise can't continue without business revenue. The enterprise income model will become more and more diversified with the increasing diversity of product 
and service. what value is each customer willing to pay? Successfully answering the question can help to generate one or more business revenue streams. Each business revenue stream may have different pricing mechanisms, such as fixed prices, bargaining, auctioning, market dependent, volume dependent or yield management. ${ }^{5}$ Diverse business revenue must be rethink and designed. This is the guarantee of business model innovation.

\section{Conclusions}

Business model innovation is a process of repeating, and it is also an endless process. This process begins with customer demand analysis, and then in turn, product \& service design, enterprise value activity organizing, business revenue creating. This is a continuous process. At the same time, any innovation which one of the four aspects is also a business model innovation.

\section{References}

1. G. Vukotich,10 Steps to Successful Change Management, ASTD Press, 2011.

2. M. E. Porter, Competitive Advantage, Beijing: Huaxia Publishing House, 2005.

3. S. Z. Wang, Innovation Path and Evolving Mechanism of Business Model for Manufacturing Enterprises Based on Value Chain, CSSS, 2011.5

4. S. Z. Wang, Research on Design and Optimize Business Model Based on the Value Chain, The Theory and Practice of Finance and Economics,2012,(3):108-111

5. A. Osterwalder, Y. Pigneur, Business Model Generation, Jonh Wiley \& Sons Inc, 2010 